\title{
Yeni Doğanlarda Deri Bakımı
}

\section{Skin Care of the Newborn}

\section{Serap Utaș}

Erciyes Üniversitesi Tıp Fakültesi, Deri ve Zührevi Hastalıklar Anabilim Dalı, Kayseri, Türkiye

\section{Özet}

Deri bariyerinin gelișimi doğumdan sonraki bir yıla kadar devam eder. Yeni doğan döneminde epidermal bariyerin inmatüritesi deri kuruluğuna, mikrobiyal kolonizasyonun hızla bașlamasına ve perkutan ilaç toksisitesine neden olur. Deri bariyeri infantlar için gerekli ve önemlidir. Deri bakımının deri bütünlüğünü koruması, toksik olmaması ve kimyasallardan dolayı gelișebilecek olası duyarlanmaya neden olmaması önemlidir. Bu derlemede yeni doğanlarda deri bakımı gözden geçirilmektedir. (Türkderm 2011; 45: 123-6) Anahtar Kelimeler: Yeni doğan, deri bakımı, epidermal deri bariyeri, banyo, emoliyentler, temizleyiciler

\section{Summary}

Development of the skin barrier continues up to one year after birth. The immaturity of the epidermal barrier in the neonatal period may cause dry skin, vulnerability to trauma, rapid onset of microbial colonization and percutaneous drug toxicity. Skin barrier is essential for infants. Skin care practices should, however, preserve skin integrity, prevent toxicity and address concerns such as potential sensitivity from chemical exposure. This article reviews the skin care of the newborns. (Turkderm 2011; 45: 123-6)

Key Words: Newborn, skin care, epidermal skin barrier, bath, emollients, cleansing

\section{Giriş}

Derimiz homeostaz, Isı düzenlenmesi, mikroplara karşı savunma, travma, toksinler ve ultraviyole radyasyonundan korumanın yanısıra, vitamin sentezi, immün gözetim ve kozmetik fonksiyonları da olan bir organımızdır. Ayrıca anne-çocuk ilişkisinde bir duyu organı gibi işlev görür., ${ }^{1,2}$

Yeni doğan derisi çok hassas, ince ve frajildir. Deri bariyeri su kaybını önleyerek vücudun homeostazının sürdürülmesinde hayati rol oynar.,4 Derinin bariyer fonksiyonu anne karnında başlar. Yakın zamanlara kadar derinin bariyer fonksiyonunun anne karnında geliştiği ve 34. gebelik haftasında tam olgunluğa ulaştığına inanııırı. Son görüşler miyadında doğanlarda derinin bariyer fonksiyonlarının tam olduğu görüşünü değiştirmiş ve gelişimin doğumdan sonraki bir yıla kadar devam ettiğini göstermiştir. ${ }^{5,6}$ Doğum bebek için ani bir çevre değişimidir. Erişkin derisine ben- zese de bazı özellikleri ile farklıdır. En önemli fark yüzey alanıdır. Infantlarda deri yüzey alanı $700 \mathrm{~cm}^{2} / \mathrm{kg}$ iken erişkinlerde bu oran $250 \mathrm{~cm}^{2} / \mathrm{kg}$ dır. Epidermis ve dermis arasındaki bağlantı zayıftır, deri ince ve daha az elastiktir. Stratum korneum geçirgenliği yüksektir ve epidermal bariyer iyi gelişmemiştir. Melanin üretimi azalmıştır. Sebase bezlerin sayısı yeterlidir ama işlevleri tam olarak gelişmediği için sebum sekresyonu azalmıştır. Benzer şekilde ter bezleri de yoğun ama daha az aktiftir. Yeni doğan ve küçük infantlarda deri yüzey pH' sı yüksektir ve serbest yağ asidi konsantrasyonu erişkin derisinden daha azdır. ${ }^{1,3}$

Infant derisinde epidermisin dermisle gevşek bağlantısından dolayı inflamatuvar süreçler esnasında kolayca büller gelişebilir. Ayrıca transepidermal su kaybı, perkütanöz absorbsiyon ve termal değişkenlik artmıştır. Epidermal bariyer tam gelişmediği için mikroorganizmalara daha duyarlıdır, irritanlara reaksiyon vermeye ve nem retansiyonuna bağlı maserasyona daha yatkındır. Yeni

Yazışma Adresi/Address for Correspondence: Dr. Serap Utaș, Erciyes Üniversitesi Tip Fakültesi, Deri ve Zührevi Hastaliklar Anabilim Dalı, Kayseri, Türkiye Tel.: +90 3524377615 Faks: +90 35243776 15/15 E-posta: sutas@erciyes.edu.tr Geliş Tarihi/Received: 23.08.2011 Kabul Tarihi/Accepted: 23.08 .2011

Türkderm-Deri Hastalıkları ve Frengi Arșivi Dergisi, Galenos Yayınevi tarafından basılmıștır. Turkderm-Archives of the Turkish Dermatology and Venerology, published by Galenos Publishing. 
doğanlarda kullanılan sabunlar ve temizleyiciler de epidermal bariyeri bozar ve derinin asit mantosunu daha kuru ve hasarlara daha hassas hale getirir. Epidermal bariyerin inmatür olması nedeniyle yeni doğanlarda deri bakımının uygun ve yaşa uyarlanmış olması son derece önemlidir. ${ }^{3}$ Bebek derisi hep özenilen bir deridir. Çok güzel, beğenilen bir deri yapısı için "bebek derisi gibi" denilir. Bu derlemede bizlerin gözbebeği olan yeni doğan bebeklerde uygun deri bakımı, dikkat edilmesi ve sakınıması gerekenler üzerinde durulmaktadır.

\section{Yeni doğanlarda deri bakımının prensipleri}

Doğumdan sonraki ilk dört hafta yeni doğan dönemidir. Normal deri bakımı, gebeliğin 37. haftasından itibaren 12 . aya kadar olan süredeki bakımı kapsayan bir terimdir. ${ }^{3}$ Günümüzde yeni doğanlarda deri bakımı toplumlar arasında farklılıklar göstermekte ve büyük ölçüde geleneklere, deneyimlere ve kültürel faktörlere dayanmaktadır. ${ }^{3}$ Deri bakım ürünleri deri bütünlüğünü korumalı, toksik olmamalı ve kimyasallardan dolayı olası duyarlanmayı göz önüne alarak hazırlanmış olmalıdır., Deri bakımında, derinin nazikçe temizlenmesi, yeterince nemlendirilmesi, deri kıvrımlarında sürtünme ve maserasyonun önlenmesi, irritanlardan ve parlak güneş ışı nlarından sakınılması gibi bazı prensiplerin üzerinde durulmalıdır., ${ }^{1,2}$ Doğumda mikrobiyal kolonizasyonun sıfır olduğu unutulmamalıdır. Koagulaz negatif stafilokoklar (Staphylococcus epidermidis) koltuk altı, kasık ve saçlı deride yavaş yavaş artar. Staphylococcus aureus anne ve bakıcıdan bulaşır. ${ }^{1,2}$ Antimikrobiyal banyolar Staphylococcus aureus sayısını azaltabilir, ancak bunlar deriden absorbe edilebilir ve özellikle prematür infantlarda toksik etkiler görülebilir. Bu nedenle yeni doğanlarda antiseptik banyolar endike değildir. ${ }^{2}$

Derinin bariyer fonksiyonunun sadece stratum korneuma sınırlı olduğunu bilmek önemlidir. Keratinositler, kolesterol, seramid ve yağ asitlerini içeren lipidden zengin bir matriksin içine yerleşmiştir. Ayrıca epidermisin yüzeyinde, çevre ile temas ettiğinde salınan farklı lipidler su ile etkileşerek derinin nem içeriğinin ve duyusal özelliklerinin devamında önemli olan hidrofilik bir film oluşturur. Bu hidrofilik filmin lipid fraksiyonu epidermisin üst tabakalarına penetre olarak epidermal bariyerin içine karışır ve onun fonksiyonlarına katkıda bulunur. Bu özellikle yeni doğanın derisinin ne ile temizlenmesi gerektiği konusunda önemlidir. ${ }^{1}$ Infant derisinin bir diğer önemli gelişimsel değişimi "asit manto" veya deri yüzey $\mathrm{pH}^{\prime}$ sının 5'den aşağıda tutulma kapasitesidir. Deri yüzey pH'sı ile mikrobiyal flora arasında yakın ilişki vardır. Deri pH'sının asidikten nötrale doğru artması derideki bakterilerin total sayısında geçici artışa ve mevcut türlerin değişimine neden olur. Bu nedenle bebek derisinin asit mantosunun devamı önemlidir. ${ }^{1}$ Yeni doğanlarda özellikle prematürlerde deri pH'sı nötral olma eğilimindedir ki bu, mikrobiyal kolonizasyonun artmasına karşı olan korumayı önemli ölçüde azaltır. Bu aynı zamanda transepidermal su kaybında artışına neden olarak epidermal bariyerin bozulmasına da yol açabilir. ${ }^{6}$

\section{ilk temizleme}

Doğumda yeni doğanın derisi verniks kazeoza, kan, mekonyum, sellüler debris ile kaplıdır. ${ }^{1}$ Hemen doğumdan sonra miyadında yeni doğan derisi, verniks kazeozanın temizlenmesi ile ilgili lokal kültürel tercihlere göre basitçe silinmeli veya suyla temizlenmelidir. ${ }^{3}$

Verniks kazeoza doğal olarak görülen, yeni doğanın deri yüzeyine yapışık, yağdan zengin birçok parçadan oluşan ve kısmen fetal sebase bezler tarafından üretilen bir maddedir. Sebase salgılardan, dökülmüş epitelyum ve lanugodan oluşur. Su (\%81), lipid (\%19 epidermal trigliseridler ve kolesterol, dermal skualen ve balmumları) ve proteinlerden (\%10) oluşur. ${ }^{1,2}$ Verniksin doğumda su kaybına karşı bariyer oluşturma, ısı düzenlenmesi ve doğal immünitede rolleri olduğu ileri sürülse de bu fonksiyonların çoğu şüphelidir.'

\section{Yeni doğanın banyosu}

Banyo, miyadında yeni doğanın kan ve verniksten temizlenmesinin ideal yoludur. 'Bebek ve anne arasındaki iletişim açısından da son derece önemlidir.2 Yeni doğanın ilk banyosunun ne zaman yapılması gerektiği konusu kültürlere göre farklılık gösterir. ${ }^{3,6}$ İnfantın ilk banyosu bebeğin vücut ısısı stabilize olduğunda ve bebek hemodinamik olarak stabil hale geldiğinde yapılmalıdır., ${ }^{1,6-11}$ Bazı kültürlerde göbek bağı düşene kadar banyo geciktirilmekte ise de yeni doğanlarda banyo göbek bağı düşmeden de yapılabilir. ${ }^{12-14}$ Birçok çalışma yeni doğan veya infantlarda banyonun bebeğe herhangi bir zararı olmadığını göstermiştir.-13,15 Doğum ağırlığı 2500 g'dan fazla olan sağlıklı miyadında doğanlarda banyo doğumdan 2-6 saat sonra yaptırılmalıdır. Düşük doğum ağırlıklı infantlarda banyo göbek bağı düşene kadar geciktirilebilir. Kış aylarında da banyo geciktirilebilir.

Yaşamın ilk birkaç haftasında banyo suyu ılık $\left(\leq 37^{\circ} \mathrm{C}\right)$ olmalıdır.13,6 Banyo yapılacak küvete konulan su, oturan infantın kalçalarına kadar ulaşmalıdır (yaklaşı $\mathrm{K} \mathrm{cm}$ ). Banyo yapılan odanın ısısı $21-22^{\circ} \mathrm{C}$ olmalıdır. Yeni doğanın banyosu için 5-10 dakika yeterlidir. ${ }^{3}$ Bazı otörler beş dakikadan fazla olmamasını, özellikle sabun kullanılıyorsa 5 dakikayı geçmemesini önermektedirler. ${ }^{12,16,17}$ Banyonun uzaması derinin hidrasyonunu artııır, hücreler arasındaki bağlantıyı azaltır ve friksiyon eşiğini düşürür. ${ }^{1,2}$ Başlangıçta steril veya içilebilir su ile yapılması yeterlidir. Infant derisindeki kan ile teması azaltmak için sağlık personeli mutlaka eldiven giymelidir. ${ }^{18}$ Illk haftalarda sabun ve temizleyicilerden kaçınılmalıdır. Yıkama sayısı ve zamanı kültürlere göre farklılıklar gösterebilmektedir. Genellikle haftada 2-3 kez yıkanması yeterlidir. Akşamları yıkama, banyonun sakinleştirici etkisi ile uykuya dalmayı kolaylaştırabilir. ${ }^{3}$

Banyo yaptırmanın sünger/lif/bezle silerek yapılan temizlemeye göre birçok üstünlüğü vardır. Banyo yaptırılan bebeklerin daha sakin, huzurlu ve hoşnut oldukları gösterilmiştir. Banyo yaptırılan bebeklerde ısı kaybı da daha az olmaktadır. Infeksiyon veya bakteriyel kolonizasyon açısından banyo veya sünger/lif/bezle temizleme arasında fark yoktur. Sağlıklı yeni doğanlarda sünger/lif/bezle temizlemede banyoya göre transepidermal su kaybının arttığı ve stratum korneum hidrasyonunun azaldığı da gösterilmiştir. ${ }^{12-14}$

Banyo esnasında bebeğin yıkanacağı küvet güvenli bir yere konulmalı ve bebeğin güvenliği sağlanmalıdır. Özellikle küçük çocuklara bebek emanet edilmemeli ve yıkama için gerekli tüm malzemeler önceden hazır edilmelidir. Banyo küveti ve banyoda kullanılan oyuncaklar kontaminasyon riski taşırlar. Bu nedenle banyodan önce bunların da dezenfekte edilmesi uygundur. Eğer banyo esnasında yağ kullanılıyorsa küvetin tabanına bir mat konmalı ve bu da düzenli olarak dezenfekte edilmelidir. ${ }^{3}$ Yeni doğan ılık odada yıkanmalı ve hemen hafif hafif vurularak kurulanmalı, havlu ile ovalanmamalıdır. ${ }^{1,3,14}$ Kurulama baştan ayağa doğru olmalıdır. Ardından ılık kuru havlu ile sarılmalıdır. Yeni doğanda banyodan 10 dakika sonra belirgin ısı düşüşü olur. Bu nedenle giysilerin nemli olmamasına özen gösterilmelidir. ${ }^{3}$ Banyodan sonra bebeğin derisinde kuruluk, kepek veya fissürler varsa uygun bir emoliyent uygulanmalıdır. Bir çok çalışma emoliyentlerin stratum korneum bütünlüğünü ve deri bariyerini koruduğunu göstermiş olup atopik dermatit gelişme riski olan bebeklerde kullanımı özellikle yararlı olabilir. ${ }^{19-21}$

Banyonun bir diğer yararı bebekle ebeveynlerin arasındaki ilişkinin gelişmesine yol açmasıdır. Banyoların ayrıca bebekler üzerinde rahatlatıcı, sakinleştirici etkisi de vardır. ${ }^{3}$

\section{Temizleyici ajanlar}

Bazı kılavuzlar temizleyici olarak sadece suyun kullanılmasını önerseler de bu kanıta dayalı değildir ve bazı çalışmalar, sadece su ile yıkamanın 
yıkama sıklığına bağı olarak infant derisini kuruttuğunu da göstermiştir. 22,23 Randomize, araştırıcı kör bir çalışmada günde 2 kez su ile temizlenen sağlıklı infantlarda 2 hafta sonra deride eritemin arttığı görülürken, hafif sıvı bir temizleyici ile yıkananlarda bu artış görülmemiştir. Sadece su ile yıkama bir hafta sonra deri pH'sında anlamlı düşüşe neden olmuş ve $\mathrm{pH}$ iki haftada normale dönmüştür. ${ }^{22}$

Temizleme deri yüzeyindeki kir, bakteri, ölü deri hücreleri, ter ve diğer debrisi çıkarma işlemidir. ${ }^{1,2}$ Bebek bakımında kullanılan sıvı temizleyiciler deriye hasar vermeden zararlı maddeleri de uzaklaştırırlar. Temizleme uygun yapılamazsa fekal enzimler bez bölgesinde dermatite yol açabilir. ${ }^{3}$ Yeni doğan derisi temizleyicilere daha duyarlıdır. Temizleyiciler alkalen sabunlar ve asidik veya nötral sentetik deterjanlar (sindetler) olarak iki grupta sınıflandırılabilir.' Bir temizleyici, sürfaktan veya deterjandan, gliserin gibi deri yumuşatıcısı, koku, renk ve koruyuculardan oluşur. İdeal olarak bebek sabunu veya temizleyicisi irritasyon yapmasın diye kokusuz ve renksiz olmalıdır., ${ }^{1,2}$ Geleneksel sabunlar genellikle alkalidir ve infant derisini kurutur ve irrite edebilirler.,

Çoğu temizleyicilerin önemli kısmı sürfaktanlardan oluşur. Sürfaktanlar, su ve hava arasındaki yüzey gerginliğini azaltarak etki ederler ve köpük etkisi yaratarak derideki yağda çözünen kirlerin temizlenmesini sağlarlar. Ancak daha yüksek köpürme gücü deri hasarı riskini artırır ve stratum korneumdan çok fazla lipid taşılar.

Sindet veya sentetik deterjanların $\mathrm{pH}^{\prime} \mathrm{s} ı$ normal deriye yakındır ve sabunlardan daha hafif ve daha az irritandır. Bunların en belirgin avantajı deri pH'sını değiştirmemeleri ve deri mikroflorasının değişmeden kalmasıdır. Dezavantajları ise çabuk parçalanmaları ve şayet nemlendirici eklenmemişse aşı rı kurutucu olmalarıdır.,

Bazı ajanlara parafin veya mineral yağlar eklenerek deriyi daha yumuşak ve esnek yapmaları sağlanır. Sabun olmayan, lipid içermeyen sindet içeren losyonlar deriyi susuz temizlerler. Kuru deriye uygulanırlar ve daha sonra yumuşak bir bezle silinirler. ${ }^{6}$

Doğumdan hemen sonra deri pH'sı 6'nın üzerindedir. Daha sonra pH 4,95'e düşer. Bu koruyucu asit manto patojenlere karşı korur. Deri pH'sını asitten nötrale dönüştüren herhangi bir girişim ve uygulama total bakteri sayısını artırır ve transepidermal su kaybını artırır. Alkali sabunla yıkadıktan sonra deri pH'sının düzelmesi en az bir saati bulur. Bu nedenle alkali pH'sı olan sabunlar yeni doğan döneminde kullanımamalıdır. Hafif sürfaktan, kimyasal ve fiziksel olarak stabil ve emoliyent içeren nötral veya hafif asidik $\mathrm{pH}^{\prime}$ lı temizleyiciler sağlıklı yeni doğan ve infantları yıkamada kullanılabilir. Yeni doğanlarda kullanılacak ideal temizleyici sıvı şeklinde, hafif olmalı, sabun içermemeli, nötral veya hafif asidik pH da olmalı, deride ve gözlerde irritasyona, gözlerde yanmaya neden olmamalıdır. ${ }^{1,3,6}$

\section{Bebek pudraları}

Pudralar, sıcak ve nemli havalarda nemi absorbe etmesi ve deri kıvrımlarında maserasyonu önlemesi açısından yararlı olsa da yeni doğan döneminde pudralardan sakınılması daha uygundur. Aşırı kullanılması ter kanalları gözeneklerini tıkayarak miliarya oluşumuna neden olur. Kazara inhalasyonu başka bir potansiyel zararıdır." Özellikle talk ve nişastalı pudralar irritasyona, pnömoniye, granülom oluşumuna ve pulmoner fibrozise neden olabilir. ${ }^{24}$

\section{Bez bölgesinin bakımı}

Bu bölge nemli ve ıslak, kapalı, bu nedenle de maserasyona ve mikroorganizmalar tarafından saldırıya yatkın bir bölgedir. Deri ayrıca idrar ve feçes gibi güçlü alkalen ajanlarla temas halindedir. Anne bezin sık değiştirilmesi konusunda uyarılmalıdır. En azından her emzirme veya besleme esnasında bez değiştirilmelidir., ${ }^{1,2}$ Deri kuru tutulmalı ve bez değişimleri esnasında havalandırılmalıdır. Sık değiştirmek mümkün değilse fizyolojik bariyer oluşturmak için mineral yağlar kullanılmalıdır. ${ }^{1}$ Temizlemek için ılık su ve yumuşak pamuklu bezler kullanılmalıdır.,17 Bölge önden arkaya doğru temizlenmelidir. Yapışık feçes için bebek losyonu gibi bir emülsiyon yüzey gerilimini azaltmak ve debrisi temizlemek için kullanılmalıdır. Döküntü olursa vazelin veya çinko oksit içeren kremler kullanılabilir. ${ }^{25}$ Vazelin bazlı veya çinko oksit içeren bariyer kremleri irritasyon riskini azaltmak için bez değişimlerinde bez bölgesine uygulanabilir. ${ }^{17}$ Temizleme bezleri pratik ve güzel kokulu olmasına rağmen, derideki lipid tabakayı çıkardıkları ve duyarlanmaya neden oldukları için kullanımları genellikle önerilmemektedir. ${ }^{6}$

\section{Saçlı derinin bakımı}

Bebekler için standart bir şampuan formülü yoktur. Saçlar kısa, ince ve kırılgan olduğu için şampuan kullanımı gerekli değildir., 2,6,17 Vücut için kullanılan ürünler saç için de kullanılabilir. ${ }^{1,2}$ Mutlaka şampuan kullanımak isteniyorsa çok az deterjan içeren, $\mathrm{pH}^{\prime}$ sı gözyaşına yakın, deriyi ve gözleri irrite etmeyecek hafif ürünlerin kullanılması uygundur. ${ }^{6}$ Bebek şampuanlarının kokusuz olması tercih edilir. ${ }^{3,6}$

Mineral veya sıvı yağların sürülmesi infantil seboreik dermatit lezyonlarının yayılmasını önler., ${ }^{1,2}$ Bebek şampuanları saçlı derideki kurut ve skuamları temizlemek için kullanılabilir. Ketokonazol, çinko pirithiyon ve selenyum sülfit gibi özgün ajanlar seboreik dermatit varsa eklenebilir.'1

\section{Diğer bölgeler}

Doğumdan sonra göbek kordonu kurur ve genellikle 5-10 gün içinde düşer. ${ }^{12}$ Göbeğe alkol, iyot gibi topikal ajanların uygulanmasından kaçınılmalıdır. Sadece klorheksidin ile ilk 10 gün göbek kordonu düşene kadar bu bölgenin temizlenmesi enfeksiyon riskini azaltır. Ellerin düzenli olarak yıkanması, göbek bağının temiz olmayan şeylerle kapatılmaması ve bezin göbekten daha aşağıda bağlanması da sağlanmalıdır. ${ }^{1,17}$ Tırnaklar kesilmeli, kısa ve temiz tutulmalıdır. ${ }^{1,2,17}$ Gözler, kaynamış suda ıslatılmış pamuklu bezlerle nazikçe temizlenmelidir.' Kulaklar da benzer şekilde temizlenmelidir. ${ }^{2}$

Yapışkan bantlar epidermal hasardan kaçınmak için nazikçe, horizontal germe yöntemiyle çıkarılmalıdır. Yapışkan çıkarıcılar deri bütünlüğünü bozabileceği için kullanılmamalıdır.,17

\section{Yeni doğanlar için emoliyentler}

Emoliyentler deriyi yumuşatan ve düzleştiren ajanlardır. Nemlendirici ve yağlandırıcılar olarak da adlandırılırlar. Esasen hayvansal veya bitkisel kökenli yağlardan oluşurlar veya alternatif olarak sentetik orijinli olabilir. Emoliyentler, vazelin, parafin gibi hidrokarbonlar, setil veya stearil alkol, bal mumu, lanolin, mineral yağlar, bitkisel yağlar veya sentetik yağlar gibi farklı maddeleri içerebilirler.,

Krem veya merhem şeklinde olabilen emoliyentlerin uygulanması yeni doğanlarda soyulmayı azaltabilir. Emoliyentler ayrıca, bariyer fonksiyonunu devam ettirmede, bez bölgesindeki irritasyonu azaltmada da rol oynarlar. ${ }^{1,2}$ Preterm infant derisi etkisiz bir epidermal bariyerdir. Prematürlere günlük emoliyent uygulanması transepidermal su kaybını önleyerek, deri bütünlüğünü koruyarak dermatit sıklığını azaltır, ama koagülaz negatif stafilokoklara bağlı infeksiyonların ve nazokomiyal infeksiyonların sıklığını artırır, bu nedenle rutin kullanı Imamalıdır. 1,2,17

\section{Topikal preparatlar}

Yeni doğan derisinin özelliklerinden dolayı kozmetik ürünlerin sağlığa uygun kimyasallar içermesi son derece önemlidir. Yeni doğanlarda vücut yüzey alanının geniş olması, ilaç metabolizmasının ve epidermal bariyerin tam gelişmemiş olması perkutanöz toksisite riskini artırır. ${ }^{3}$ Topikal antiseptik olarak, kapatılan bölgelerde alkol kullanıldığında 
hemorajik nekroz gelişebilir. Özellikle düşük doğum ağırlıklı bebeklerde temizlik için alkol kullanıldığında yanıklar oluşabilir. Bu nedenle yeni doğan ünitelerinde alkolden kaçınılması uygun olur. 6, 17,26,27 Klorheksidin $\% 0,5$ oranında kullanıldığında etkili bir antiseptik ve oldukça güvenli bir alternatiftir. ${ }^{27}$ Yeni doğan derisinde aşırı iyot kullanımı ciddi ve geçici hipotiroidizme neden olabilir. Bu nedenle iyotlu solüsyonlardan yeni doğan döneminde sakınılması uygun olur. ${ }^{2,17}$. Böyle bir durumla karşılaşıldığında, özellikle de prematür bebeklerde tiroid hormon seviyesi mutlaka ölçülmelidir. ${ }^{17,28}$

Lokal anesteziklerde bulunan prilokain fazla kullanıldığında methemoglobinemiye neden olur. Yirmi beş gram prilokain maksimum 10 $\mathrm{cm}^{2}$ lik alana uygulanmalıdır. ${ }^{29,30}$

Birçok emoliyentin içerisinde bulunan propilen glikol, özellikle \%5 konsantrasyondan daha yoğun kullanılırsa deride irritasyona ve yanmaya neden olabilir. ${ }^{31}$

Sodyum lauril sülfat lipid bariyeri tahrip eden potent bir irritandır, deride inflamasyona ve deri katlarının ayrılmasına neden olur. Triklosan gibi diğer ürünlerle kombine edildiğinde deride uzun süre kalabilir. Sodyum lauret sülfat ve amonyum lauret sülfat duş jelleri ve banyo köpüklerinde bulunurlar ve deride irritasyona neden olabilirler. ${ }^{31}$ Şampuan, losyon ve temizleme bezlerinde bulunan parabenler ise kontakt dermatite neden olabilirler. ${ }^{31}$

Yeni doğan, doğumla birlikte yeni bir ortama uyum sağlamaya çalışır. Bu süreçteki yeni doğanın derisi travma ve infeksiyonlara son derece hassas ve yatkındır. Deri bariyerinin korunması bu dönemde hayati önem taşır. Yeni doğan derisinin bariyer fonksiyonları tam olarak gelişmediği için bu dönemde derinin bariyer fonksiyonlarını bozmayacak, bebeğe zarar vermeyecek uygun yöntemlerin ve deri bakım ürünlerinin kullanı Iması çok önemlidir.

\section{Kaynaklar}

1. Sarkar R, Basu S, Agrawal RK, Gupta P: Skin care for the newborn. Indian Pediatr 2010;47:593-8.

2. Stalder JF: Skin care of the newborn. In. Textbook of Pediatric Dermatology. Eds. Harper J, Oranje A, Prose N: Blackwell Publishing. 2nd ed. 2006:48-54

3. Blume-Peytavi U, Cork MJ, Faergemann J, Szczapa J, Vanaclocha F, Gelmetti C: Bathing and cleansing in newborns from day 1 to first year of life: recommendations from a European round table meeting. JEADV 2009;23:751-9.

4. Cork MJ: The importance of skin barrier function. J Dermatolog Treat 1997:8:7-13.

5. Stamatas GN, Nikolovski J, Mack MC, Kollias N: Infant skin physiology and development during the first years of life: a review of recent findings based on in vivo studies. Int J Cosmet Sci 2011;33:17-24.

6. Fernandes JD, Machado $M C$, Oliveira ZN: Children and newborn skin care and prevention. An Bras Dermatol 2011;86:102-10.

7. Behring A, Vezeau TM, Fink R: Timing of the newborn first bath: a replication. Neonatal Netw 2003;22:39-46.
8. Penny-MacGillivray T: A newborn's first bath: when? J Obstet Gynecol Neonatal Nurs 1996;25:481-7.

9. Varda KE, Behnke RS: The effect of timing of initial bath on newborn's temperature. J Obstet Gynecol Neonatal Nurs 2000;29:27-32.

10. Darmstadt GL, Dinulos JG: Neonatal skin care. Pediatr Clin North Am 2000; $47: 757-82$.

11. Medves JM, O'Brien B: The effect of bather and location of first bath on maintaining thermal stability in newborns. J Obstet Gynecol Neonatal Nurs 2004;33:175-82.

12. Henningsson A, Nystrom B, Tunnell R: Bathing or washing babies after birth? Lancet 1981;2:1401-3.

13. Bryanton J, Walsh $D$, Barrett $M$, Gaudet $D$ : Tub bathing versus traditional sponge bathing for the newborn. J Obstet Gynecol Neonatal Nurs 2004;33:704-12.

14. Garcia Bartels N, Mleczko A, Schink T, Proquitté H, Wauer RR, Blume-Peytavi $U$, et al: Influence of bathing or washing on skin barrier function in newborns during the first four weeks of life. Skin Pharmacol Physiol 2009;22:248-57.

15. Anderson GC, Lane AE, Chang HP. Axillary temperature in transitional newborn infants before and after tub bath. Appl Nurs Res 1995;8:123-8.

16. Gelmetti C: Skin cleansing in children. J Eur Acad Dermatol Venereol 2001;15:12-5.

17. Afsar FS: Skin care for preterm and term neonates. Clin Exp Dermatol 2009;34:855-8.

18. Centers for Disease Control. Leads from the MMWR. Update: universal precautions for prevention of transmission of human immunodeficiency virus, hepatitis $B$ virus, and other bloodborne pathogens in health-care settings. JAMA 1988;260:462-5.

19. Bergstrom A, Byaruhanga R, Okong P: The impact of newborn bathing on the prevalence of neonatal hypothermia in Uganda: a randomized, controlled trial. Acta Paediatr 2005;94:1462-7.

20. Ghadially R, Halkier-Sorensen L, Elias PM: Effects of petrolatum on stratum corneum structure and function. J Am Acad Dermatol 1992;26:387-96.

21. Lane AT, Drost SS. Effects of repeated application of emollient cream to premature neonates' skin. Pediatrics 1993;92:415-9.

22. Hiscock H. The crying baby. Aust Fam Physician 2006;35:680-4.

23. Galzote C, Dizon MV, Estanislao R, Mathew N: Opportunities for mild and effective infant cleansing beyond water alone. I Am Acad Dermatol 2007:56:AB158.

24. Mofenson HC, Greensher JD: Baby powder: the hazard. Pediatrics 1981;68:265-6.

25. Adam R Skin care of the diaper area. Pediatr Dermatol 2008;25:427-33.

26. Harpin $\mathrm{V}$, Rutter N: Percutaneous alcohol absorbtion and skin necrosis in a preterm infant. Arch Dis Child 1982;57:477-9.

27. Mannan K, Chow P, Lissauer T, Godambe S: Mistaken identity of skin cleansing solution leading to extensive chemical burns in an extremely preterm infant. Acta Paediatr 2007;96:1536-7.

28. Khashu M, Chessex P, Chanoine JP: lodine overload and severe hypothyroidism in a premature neonate. J Pediatr Surg 2005;40:E1-4.

29. Darmstad GL, Dinulus JG: Neonatal skin care. Ped Clin North Am 2000;47:757-82.

30. Shachor-Meyouhas Y, Galbraith R, Shavit I: Application of topical analgesia in triage: a potential for harm. J Emerg Med 2008:35:39-41.

31. Trotter S: Neonatal skincare: why change is vital. RCM Midwives 2006;9:134-8. 